\title{
A MEDIAÇÃo E A ARBITRAGEM COMO SOLUÇõES DE CONFLITOS NO ÂMBITO DO DIREITO ADMINISTRATIVO
}

\section{MEDIATION AND ARBITRATION AS SOLUTIONS FOR CONFLICTS UNDER ADMINISTRATIVE LAW}

Paulo Roberto do Nascimento Teixeira*

Resumo: $O$ presente artigo analisa a necessidade de eficiência na Administração Pública e sua relação com os volumes e custos do processo judicial no Brasil, a evolução legislativa que culminou com o desenvolvimento de meios alternativos de conflitos no Direito Administrativo brasileiro permitindo diversos mecanismos mais adequados em relação à jurisdição, em especial a arbitragem e a mediação. É exposta também a falta de efetividade de tais meios, em especial a partir da ausência de regulamentação do tema nos entes federados e são sugeridas possíveis alternativas para um maior alcance e aplicação da mediação e da arbitragem a nível nacional pela Administração.

Palavras-chave: Direito Administrativo Contemporâneo. Administração Pública. Meios Alternativos de Soluções de Conflitos.

Abstract: This article analyzes the need for efficiency in the Public Administration and its relation to the volumes and costs of the judicial process in Brazil, the legislative evolution that culminated with the development of alternative means of conflicts in the Brazilian Administrative Law allowing several more adequate mechanisms in relation to the law. jurisdiction, in particular arbitration and mediation. The ineffectiveness of such means is also exposed, especially from the lack of regulation of the issue in the federated entities and possible alternatives are suggested for greater scope and application of mediation and arbitration at national level by the Administration.

Keywords: Contemporary Administrative Law. Public Administration. Alternative Means of Conflict Resolution.

\footnotetext{
* Bacharel em Direito pelo Centro Universitário Augusto Motta (UNISUAM). Técnico Judiciário do Tribunal Regional Eleitoral do Rio de Janeiro. E-mail: paulorobertonteixeira@gmail.com.
} 


\section{INTRODUÇÃO}

$\mathrm{Na}$ atualidade o excesso da rigidez da Administração Pública, os gastos com processos judiciais, o acúmulo de processos e os impactos de institutos jurídicos sob o prisma econômico são alvo de reflexão. Estes elementos levam ao uso mais racional e eficiente possível do Direito.

Os meios alternativos de solução de conflitos a disposição da Administração Pública são uma forma de racionalização, o que leva a escolha do tema. Institutos como a Arbitragem, o dispute board, conciliações, mediações e acordos em geral judiciais ou extrajudiciais são mecanismos que se desenvolveram e foram integrados à legislação brasileira. A Administração Pública é um contumaz litigante (repeat player) e a morosidade em solucionar estes litígios ocupa recursos tanto do Judiciário quanto do Executivo.

Diante disso constata-se que os mecanismos em ascensão na legislação que propõem alternativas mais céleres e consensuais são ferramentas sobre as quais se faz necessária reflexão e propostas para sua maior aplicabilidade.

\section{PRINCÍPIO DA EFICIÊNCIA E A SUA EVENTUAL VIOLAÇÃO DIANTE DO EXCESSO DE LITÍGIOS}

\subsection{O princípio da eficiência como norteador da Administração Pública Gerencial}

A doutrina administrativista de largo afirma que a EC 19/1998, tinha em seu propósito final, a mudança do paradigma administrativo, rompendo com um modelo burocrático e migrando para um modelo gerencial. E isto significa o Estado não deveria mais buscar somente que sua atuação fosse legal, mas também otimizada com a utilização racional de seus recursos, a satisfação do cidadão e os resultados positivos sob o prisma da gestão. Desta perspectiva decorre a expressão "Administração Pública de Resultados." Nesta esteira é possível afirmar que há para a Administração Pública brasileira um dever de produzir o melhor resultado com o menor custo possível.

\subsection{A Fazenda Pública como Litigante Contumaz}


Segundo Marcelo Veiga Franco, professor e pesquisador da UFMG, a Fazenda Pública é o principal repeat player do Brasil (repeat player é uma expressão importada do direito norte-americano para se referir a um litigante habitual), é certo que os processos judiciais tornaram-se sinônimos de morosidade dado ao fato de que normalmente demoram a serem finalizados. Uma vez que nosso foco é a Fazenda cite-se que no ano de 2011, em pesquisa do Instituto de Pesquisa Econômica Aplicada (IPEA) apurou-se que o tempo médio das Execuções Fiscais era de 8 anos, 2 meses e 9 dias e o custo médio desses processo era de $R \$ 4.685,39$. Se tratando de dados um pouco mais recentes de processos judiciais em geral em pesquisa realizada pelo IDP, publicada por Felipe Recondo do periódico jurídico Jota no ano de 2018, referente ao ano de 2013 os custos médios eram da seguinte forma no Estado do Rio de Janeiro, na Justiça Estadual em 2010 era de R\$1.513,56, em 2011 de $\mathrm{R} \$ 1.378,96$, em 2012 de $\mathrm{R} \$$ 1.503,59 e em 2013 de $\mathrm{R} \$ 1.464,79$.

A fim de sistematizar os dados apresenta-se a tabela a seguir com as informações citadas:

\section{Tabela 1 - Custos médios de Processos Judiciais}

\begin{tabular}{|l|l|l|l|l|}
\hline Tipo de Processo: & Ano: & Custo: & $\begin{array}{l}\text { Tempo Médio } \\
\text { de duração: }\end{array}$ & Fonte: \\
\hline Execuções Fiscais no País & 2011 & $\mathrm{R} \$ 4.685,39$ & $\begin{array}{l}8 \text { anos e dois } \\
\text { meses }\end{array}$ & IPEA \\
\hline $\begin{array}{l}\text { Processos em geral no Rio } \\
\text { de Janeiro }\end{array}$ & 2010 & $\mathrm{R} \$ 1.513,56$ & $*$ & IDP \\
\hline $\begin{array}{l}\text { Processos em geral no Rio } \\
\text { de Janeiro }\end{array}$ & 2011 & $\mathrm{R} \$ 1.378,96$ & $*$ & IDP \\
\hline $\begin{array}{l}\text { Processos em geral no Rio } \\
\text { de Janeiro }\end{array}$ & 2012 & $\mathrm{R} \$ 1.503,59$ & $*$ & IDP \\
\hline $\begin{array}{l}\text { Processos em geral no Rio } \\
\text { de Janeiro }\end{array}$ & 2013 & $\mathrm{R} \$ 1.464,79$ & $*$ & IDP \\
\hline
\end{tabular}

Fonte: IPEA, 2011. *A pesquisa do IDP apurou apenas os custos.

Verifica-se que é consideravelmente alto o valor total com estes custos em um acervo de aproximadamente 80 milhões de processos no Judiciário Brasileiro, 
segundo levantamento do Conselho Nacional de Justiça (CNJ) do ano de 2018. Em matéria jornalística do Estado do Rio Grande do Sul, publicada este ano, demonstrando as estatísticas da judicialização da saúde em alguns Municípios daquele Estado foram possíveis encontrar os seguintes dados:

- Algumas prefeituras aplicam, em razão de processos judiciais, $40 \%$ do orçamento na área da saúde, acima dos $15 \%$ constitucionais. No último levantamento feito no início deste ano foram contabilizadas 90 mil ações que judicializam a questão da saúde, enquanto a Secretaria Estadual de Saúde do Rio Grande do Sul possui 65 mil pacientes em atendimentos por ordem judicial de medicamentos, o gasto em medicamentos foi de $R \$ 436$ milhões em 2018.

- A Secretaria enfatiza que a judicialização do tema naquele Estado beneficia um pequeno número de pessoas em detrimento de outras. Destaca-se na matéria que Judiciário, Executivo e Defensoria daquele Estado estão empenhados em prevenir a judicialização com a implementação de comitês para prevenção da discussão judicial.

- Os gastos de quatro municípios com ações judiciais somente envolvendo o tema da saúde, quais sejam: $R \$ 764.733,57$, no Município de Campo Bom; R\$135.509,52, no Município de Ivoti; R\$1.453.000,00, no Município de Novo Hamburgo e R\$762.778,82 no Município de Sapiranga. Dados referentes aos cinco primeiros meses de 2019.

\section{Tabela 2 - Custos dos Municípios com Ações Judiciais envolvendo saúde na Região de Novo Hamburgo - RS}

\begin{tabular}{|l|l|}
\hline $\begin{array}{l}\text { Custo da judicialização da saúde até } \\
\text { maio de } 2019:\end{array}$ & Município: \\
\hline$R \$ 764.733,57$ & Campo Bom \\
\hline$R \$ 135.509,52$ & Ivoti \\
\hline$R \$ 1.453 .000,00$ & Novo Hamburgo \\
\hline$R \$ 762.778,82$ & Sapiranga \\
\hline
\end{tabular}

Fonte: JORNAL NOVO HAMBURGO, 2019. 
Ressalte-se ainda que o Estado figura nos processos por vezes em duas, três ou até mesmo mais frentes. Basta recordar que em muitos processos figuram de um lado o Ministério Público e de outro um dos Entes Federativos ou suas Administrações Indiretas. Por vezes a Defensoria Pública também atua contra um dos Entes Federados e ainda há processos coletivos nos quais todos estes atores estão envolvidos no litígio.

É necessário salientar que em qualquer hipótese está presente o Judiciário que também faz parte da estrutura estatal e deve ser igualmente norteado pelo princípio da eficiência, tanto enquanto gestor do processo judicial (Art. $8^{\circ}$ do NCPC), quanto como integrante da Administração Pública. (Art. 37, CRFB/88).

Há por consequente (ou havia) aparente violação ao princípio da eficiência, infringido por várias instituições estatais na medida em que se valia da judicialização para boa parte dos conflitos em que a Fazenda estava presente.

É possível que tal cenário onde se privilegie o processo judicial em detrimento dos demais meios de solução de conflitos seja fruto de dois aspectos culturais presentes na sociedade brasileira, quais sejam, a "cultura da sentença" (WATANABE, 2005) e o "mito do governo grátis" (CASTRO, 2014, p. 7), a primeira expressão do processualista Kazuo Watanabe e esta última toma-se por empréstimo da obra do economista Paulo Rabello de Castro.

A cultura da sentença é marcada pela formação do jurista e a ênfase de seu trabalho como a solução dos problemas por meio do processo judicial, que culmina com a sentença, transformando-se o processo e o seu desfecho de modo litigioso uma verdadeira panaceia, tal cultura ainda é forte e predominante em nosso meio. Nas palavras do Professor Kazuo Watanabe:

\footnotetext{
"... a formação acadêmica dos nossos operadores do direito, que é voltada, fundamentalmente, para a solução contenciosa e adjudicada dos conflitos de interesses. Ou seja, toda ênfase é dada a solução de conflitos por meio do processo judicial, em que é proferida uma sentença, que constitui a solução imperativa dada pelo representante do Estado. O que se privilegia é a solução pelo critério do "certo ou errado", do "preto ou branco", sem qualquer espaço para a adequação da solução, pelo concurso das vontades das partes, à especificidade de cada caso." (CASTRO, 2014).
}

O mito do governo grátis tomando exatamente o conceito apresentado por Paulo Rabelo de Castro é: 
"O ponto culminante do ilusionismo político é o governo grátis. O mito do governante que seja capaz de produzir benefícios coletivos sem qualquer custo para a sociedade é a forma mais sofisticada de se criar a ilusão coletiva da gratuidade a respeito de tudo que seja ou provenha do setor público(...)" (CASTRO, 2014, p. 22).

Não é possível ignorar que o processo tem um custo, que autos físicos ou eletrônicos não são só papel ou dados localizados em computadores ou repartições públicas e que a mão-de-obra que os operacionaliza não é gratuita. Em todo o mundo o Direito tem sido marcado pela sua Análise Econômica:

\footnotetext{
"A AED é uma disciplina que estuda o Direito e suas instituições, tendo como base a racionalidade individual. A AED pode ser definida como a aplicação da teoria econômica e dos métodos econométricos no exame da formação, da estrutura, dos processos e dos impactos do direito e das instituições legais." (PORTO, 2013).
}

Portanto sob pena de incorrer em um "mito do processo grátis" é necessário haver cautela econômica com os custos da litigiosidade, em especial envolvendo a Administração Pública.

\section{O DESENVOLVIMENTO DE MEIOS ALTERNATIVOS À JURISDIÇÃo NO ÂMBITO DO DIREITO ADMINISTRATIVO}

Percebendo a realidade apontada anteriormente, paulatinamente a doutrina, a prática jurídica administrativa, as decisões judiciais, a jurisprudência dos tribunais e o legislador foram desenvolvendo meios mais céleres, baratos e por vezes consensuais de pacificação. Nem sempre foi fácil a introdução destes mecanismos, pois muitas vezes a visão tradicional administrativista via com desconfiança, principalmente em razão da visão rígida de princípios como legalidade, supremacia e indisponibilidade do interesse público, logo pensava-se que o processo judicial também seria indisponível.

Todavia consolida-se nos últimos anos entendimento diverso que está em sentido oposto, nas palavras de Marco Antônio Rodrigues: "A indisponibilidade do interesse público não representa a indisponibilidade do processo judicial." Passa-se a discorrer sobre alguns dos meios que foram se desenvolvendo no âmbito da 
Administração, em especial sobre a Mediação e a Arbitragem. Tais meios têm sido chamados de Alternative Dispute Resolution (ADR) e na esfera processual civil de Multidoor Courthouse System (conhecido na doutrina brasileira como Sistema de Múltiplas portas).

\subsection{Os acordos}

Como dito anteriormente boa parte dos processos judiciais envolvem mais de uma instituição e/ou ente público. A fim de evitar processos judiciais morosos, que por vezes transmitem a sensação de ineficácia e impunidade é possível que os legitimados a propor ações civis públicas, em especial o Ministério Público e a Defensoria Pública celebrem acordos com os Entes da Administração Direta e Indireta para que se adequem a eventuais violações a direitos, são os chamados TAC (Termos de Ajustamento de Conduta) - previsto na Lei 7.347/85 em seu Art. 50, § 60.

Justamente temendo por repercussões econômicas desastrosas previram as leis $12.529 / 11$ e $12.846 / 13$ os chamados acordos de leniência entre a autoridade no topo da hierarquia da instituição pública e pessoas jurídicas responsáveis por atos lesivos que venham a de fato cooperar com investigações e processos administrativos, sendo necessários alguns resultados específicos na forma das leis citadas.

Nesta esteira, cite-se a recente alteração à Lei de Introdução as Normas Gerais do Direito Brasileiro pela Lei $13.655 / 18$ que prevê celebrações de compromisso para pacificação de conflitos envolvendo situações contenciosas, cite-se o dispositivo legal:

\footnotetext{
"Art. 26. Para eliminar irregularidade, incerteza jurídica ou situação contenciosa na aplicação do direito público, inclusive no caso de expedição de licença, a autoridade administrativa poderá, após oitiva do órgão jurídico e, quando for o caso, após realização de consulta pública, e presentes razões de relevante interesse geral, celebrar compromisso com os interessados, observada a legislação aplicável, o qual só produzirá efeitos a partir de sua publicação oficial."
}

\subsection{Os dispute-boards}


O dispute-board tem sido adaptado para o português como comitê de resoluções de conflito, sua origem apontada é norte-americana da década de 70 em contrato celebrado para a construção do túnel de Eisenhower. O dispute-board é indicado pelos co-contratantes na celebração do negócio jurídico, as partes indicam um colegiado de especialistas que visam solucionar conflitos no ínterim do contrato, o nível de imposição das decisões deste comitê variam conforme o pactuado. (OLIVEIRA, 2018, p. 513-514). Cite-se o importante avanço envolvendo o Município de São Paulo que regulamentou o dispute board no âmbito daquela municipalidade por meio da Lei $16.873 / 18$.

\title{
3.3 A Arbitragem
}

Tradicionalmente a doutrina jurídica e até mesmo a jurisprudência dos Tribunais de Contas, em nome da legalidade, da supremacia do interesse público e da indisponibilidade do interesse público foram responsáveis por rechaçar a possibilidade da utilização da arbitragem envolvendo à Administração Pública. Seguem-se algumas considerações sobre este histórico:

\begin{abstract}
"A questão do uso da arbitragem pela Administração Pública no Brasil já foi mais controversa, o que se verifica hoje é uma maior aceitação do instituto para a solução dos litígios envolvendo o Estado como contratante, inclusive com autorização legislativa para tanto. (...)

(...) Por outro lado, decisão do Tribunal de Contas da União, em caso envolvendo validação de cláusula arbitral ajustada por uma empresa pública com particulares, declarou: [...] a aplicação aqui da cláusula de compromisso arbitral encontra um óbice intransponível, qual seja a ausência de autorização legal. $O$ fato de a outras modalidades de contratos administrativos ser possibilitada a inclusão de cláusula de arbitragem, tal como previsto no inciso $X$ do art. 43 da Lei $n^{\circ}$ 9.478/1997126, não permite a extensão por analogia desses dispositivos às avenças aqui tratadas. A Administração é regida pelo princípio da legalidade e a arbitragem é cláusula de exceção à regra de submissão dos conflitos ao Poder Judiciário, somente podendo ser aplicada com expressa autorização legal." (LOCKS, 2012, p. 1718).
\end{abstract}

Cumpre recordar que a Arbitragem não é um acordo em si (por isso é classificada como meio de hetero-composição), embora possua certa dose de consensualidade (pois é necessário que haja uma predisposição das partes em 
submeter o seu conflito a um Árbitro por meio de cláusula contratual - cláusula arbitral - ou por um acordo - compromisso arbitral), no Brasil este meio alternativo à jurisdição é regulamentado pela lei 9307/98 e hoje se debate na seara processualista com forte tendência ao reconhecimento da arbitragem como tendo a natureza de jurisdição. (PINHO, 2018).

O legislador desenvolveu a questão da utilização da arbitragem pela Administração Pública e, ao longo dos anos, inseriu expressamente em diversas leis a possibilidade de utilização de tais mecanismos. Cite-se: Lei 11.196/05 que inseriu expressamente a possibilidade de utilização da Arbitragem em contratos de concessão de serviços públicos in verbis.

Art. 23-A. O contrato de concessão poderá prever o emprego de mecanismos privados para resolução de disputas decorrentes ou relacionadas ao contrato, inclusive a arbitragem, a ser realizada no Brasil e em língua portuguesa, nos termos da Lei $n^{0} 9.307$, de 23 de setembro de 1996.

Também a Lei 11.079/04 (Lei das PPP) que previu a utilização daquele meio de hetero-composição aos contratos de Parceria Público Privada. Segue-se a sua redação:

Art. 11. O instrumento convocatório conterá minuta do contrato, indicará expressamente a submissão da licitação às normas desta Lei e observará, no que couber, os $\S \S 3^{\circ}$ e $4^{\circ}$ do art. 15 , os arts. 18,19 e 1995 , podendo ainda prever:

(...)

III - o emprego dos mecanismos privados de resolução de disputas, inclusive a arbitragem, a ser realizada no Brasil e em língua portuguesa, nos termos da Lei no 9.307, de 23 de setembro de 1996, para dirimir conflitos decorrentes ou relacionados ao contrato.

Em 2015 a Lei de arbitragem sofreu uma reforma que passou a incluir, de modo explícito, a possibilidade de sua utilização pela Administração Pública (arts. 10, $\S 1^{\circ}$ e $2^{\circ}$, Lei $\left.9307 / 96\right)$.

Destaque-se que há algumas especificidades na Arbitragem envolvendo a Administração. A Arbitragem sempre será de direito, jamais de equidade, também necessariamente se desenvolverá em língua portuguesa, deverá versar apenas sobre direitos patrimoniais disponíveis e deverá respeitar o princípio da publicidade (há 
discussões doutrinárias a respeito dos limites entre confidencialidade e publicidade envolvendo a Administração Pública) (PINHO, 2017).

No plano legislativo ocorreu importante acréscimo sobre o tema. A lei que regulamenta as desapropriações foi alterada pela Lei 13.867/19, a fim de que a discussão do montante indenizatório destinado ao particular que teve seu bem desapropriado possa ser discutida em sede arbitragem (em acordos e mediações também). Percebe-se assim uma crescente legitimação pelo legislador de lançar mão da Arbitragem para pacificação entre particular e Estado.

Atualmente, a jurisprudência vislumbra a utilização da Arbitragem pela Administração Pública, cite-se a ADI 5065, na qual o STF, não obstante a menção se dar em obter dictum, cita tal alternativa:

"DIREITO CONSTITUCIONAL, CIVIL E ADMINISTRATIVO. GESTÃO COLETIVA DE DIREITOS AUTORAIS. LEI NO 12.583/2013. NOVO MARCO REGULATÓRIO SETORIAL. ARGUIÇÃO DE VIOLAÇÕES FORMAIS E MATERIAIS À CONSTITUIÇÃO DA REPÚBLICA FEDERATIVA DO BRASIL. NÃO OCORRÊNCIA. ESCOLHAS REGULATÓRIAS TRANSPARENTES E CONSISTENTES. MARGEM DE CONFORMAÇÃO LEGISLATIVA RESPEITADA. DEFERÊNCIA JUDICIAL. PEDIDO CONHECIDO E JULGADO IMPROCEDENTE. (...)

28. A mediação e a arbitragem, enquanto métodos voluntários e alternativos à jurisdição estatal, (i) minimizam a demanda pelo Poder Judiciário e (ii) propiciam a análise dos conflitos intersubjetivos por técnicos e especialistas no tema. 29. A novel disciplina legal deixa evidente o caráter voluntário da submissão de eventuais litígios aos procedimentos alternativos de solução perante órgão da Administração Pública federal. Essa voluntariedade decorre diretamente da Constituição da República (CRFB, art. 50, XXXV), como reconhecido pelo STF (SE no 5.206) e devidamente respeitado pelo legislador ordinário (Lei no 9.610/1998, art. 100-B), pelo Chefe do Poder Executivo federal (Decreto no 8.469/2015, art. 25) e pelo Ministério da Cultura (IN no 4/2015, art. $2^{\circ}$ ). (Supremo Tribunal Federal STF - Ação Direta de Inconstitucionalidade 5.065/DF, Relator: Luiz Fux, DJ: 27/10/2016, 2016.

\subsection{A Mediação}

A Mediação, ao contrário da Arbitragem, é considerada uma forma de auto composição, pois o terceiro envolvido não toma uma decisão impositiva, mas ajuda as partes a conhecerem todas as informações necessárias para que os próprios cheguem a uma solução consensual. (RODRIGUES, 2016, p. 385).

A atual lei de Mediação (Lei 13.140/15) permite a utilização deste meio de solução para a Fazenda Pública Federal (Arts. 35 a 40) - cite-se de antemão a 
necessidade de extensão de normas similares ao âmbito de Estados e Municípios Os requisitos da mediação são a autorização do Advogado Geral da União (chefe do sistema jurídico da Administração Pública Federal) com base na jurisprudência sólida dos Tribunais superiores ou em parecer da AGU homologado pelo Presidente. A opção pela mediação em geral implica na renúncia pelo administrado a manejar recursos administrativos ou processos judiciais, bem como se houver eventual processo em curso deverá haver renúncia expressa pelo administrado ao processo.

Deve haver também resolução administrativa própria que regulamente a aplicação daquela regra a casos idênticos. Ressalte-se que convencionalmente recomenda-se a mediação a conflitos em que as partes já possuem algum vínculo anterior, sendo recomendável por exemplos para conflitos entre a Administração Pública e seus servidores. Há ainda na doutrina algumas discussões sobre a necessidade de sopesar a confidencialidade da mediação e o princípio constitucional da publicidade administrativa. (PINHO, 2017).

\subsection{Conciliação}

A conciliação não obstante sua semelhança com a mediação é destinada a casos onde as partes não possuem necessariamente um vínculo prévio. A atual lei de mediação citada anteriormente permite a auto composição pela Administração Pública o que envolve a conciliação. Saliente-se existir na doutrina quem a defenda como apenas uma espécie de mediação.

\subsubsection{A MP 899/2019 (Contribuinte Legal) e as Transações em Matéria Tributária}

Similar ao que ocorre em menor escala em outros entes federativos, a União, por meio da medida provisória 899/19 - ainda não convertida em lei até o fechamento deste artigo, a qual encontra-se na relatoria de Comissão Mista para deliberação e tramita em regime de urgência - instituiu permissões a transações entre a Fazenda e o contribuinte que versam sobre tributos devidos. A diferença em relação a programas de menor vulto em outros entes é que mesmo créditos já inscritos em dívida ativa poderão ser alvos de acordos. Há opções na referida Medida 
Provisória para celebração de acordos tanto por iniciativa da Fazenda, quanto pelo próprio devedor e modalidades que abrangem descontos.

A referida Medida Provisória tem sido denominada "Contribuinte Legal." A MP acaba por regulamentar o Art. 171, CTN, que prevê como forma de extinção do crédito tributário a transação.

A Medida Provisória prevê possibilidades de descontos e parcelamentos, em especial para dívidas de grande monta de pessoas físicas e microempresas. O que vai ao encontro da análise econômica sobre a qual se expõe o presente artigo, uma vez que ao mesmo tempo em que gera receita para a União, libera o indivíduo de suas dívidas estimulando a economia, bem como exerce certa função regulatória ao estimular o pagamento de dívidas por pequenas empresas, dando-as condições de soerguimento. Seguem-se alguns dispositivos da Medida do "Contribuinte Legal":

Art. $1^{\circ}$ Esta Medida Provisória estabelece os requisitos e as condições para que a União e os devedores ou as partes adversas realizem transação resolutiva de litígio, nos termos do art. 171 da Lei no 5.172, de 25 de outubro de 1966 - Código Tributário Nacional. (...)

$\S 3^{\circ}$ Aplica-se o disposto nesta Medida Provisória: I - aos créditos tributários não judicializados sob a administração da Secretaria Especial da Receita Federal do Brasil do Ministério da Economia;

II - à dívida ativa e aos tributos da União, cuja inscrição, cobrança ou representação incumbam à Procuradoria-Geral da Fazenda Nacional, nos termos do disposto no art. 12 da Lei Complementar no 73, de 10 de fevereiro de 1993; e,

III - no que couber, à dívida ativa das autarquias e das fundações públicas federais, cuja inscrição, cobrança e representação incumbam à ProcuradoriaGeral Federal e aos créditos cuja cobrança seja competência da Procuradoria-Geral da União, nos termos de ato do Advogado-Geral da União e sem prejuízo do disposto na Lei no 9.469, de 10 de julho de 1997. (...)

Art. $5^{\circ} \mathrm{A}$ transação poderá dispor sobre:

I - a concessão de descontos em créditos inscritos em dívida ativa da União que, a exclusivo critério da autoridade fazendária, sejam classificados como irrecuperáveis ou de difícil recuperação, desde que inexistam indícios de esvaziamento patrimonial fraudulento;

II - os prazos e as formas de pagamento, incluído o diferimento e a moratória; e

III - o oferecimento, a substituição ou a alienação de garantias e de constrições. (...)

$\S 3^{\circ} \mathrm{A}$ proposta de transação observará os seguintes limites:

I - quitação em até oitenta e quatro meses, contados da data da formalização da transação; e

II - redução de até cinquenta por cento do valor total dos créditos a serem transacionados.

$\S 4^{\circ} \mathrm{Na}$ hipótese de transação que envolva pessoa natural, microempresa ou empresa de pequeno porte o prazo de que trata o inciso I do $\S 3^{\circ}$ será 
de até cem meses e a redução de que trata o inciso II do $\S 3^{\circ}$ será de até setenta por cento.

\section{A EFETIVIDADE DAS ALTERNATIVE DISPUTE RESOLUTION NA ADMINISTRAÇÃO PÚBLICA BRASILEIRA}

Não obstante os exemplos citados e os avanços legislativos contundentes feitos nos últimos anos ainda é pouca a efetividade destas legislações, principalmente quando recordamos que a Administração Pública é exercida pelos Entes Federativos, seus órgãos e Entidades, no âmbito de 26 Estados, Distrito Federal e 5.569 Municípios. Passa-se a demonstrar que ainda é passível de otimização a adesão às Alternative Dispute Resolution em âmbito nacional.

Devemos lembrar que o Brasil é uma federação e como tal possui Entes autônomos, em especial no campo da legislação, posto que a Constituição Federal Ihes dá tal competência. Logo, apesar dos avanços legislativos federais e nacionais. Faz-se necessário que os Entes suplementem a legislação nacional em seus âmbitos, bem como que a própria Administração Pública que possui o seu poder regulamentar o qual se destina a regulamentar à própria legislação por meios infra legais (em especial decretos). A efetividade das ADR nas Administrações Públicas brasileiras depende da existência de normas que apliquem e adéquem a legislação nacional à realidade específica de cada Estado ou Município.

\subsection{A regulamentação dos Meios Alternativos de Solução de Conflitos no âmbito dos demais Entes da Federação}

A Mediação e a Arbitragem foram expressamente permitidas à Administração Pública pelo legislador nacional no ano de 2015, conforme já mencionado, no entanto até o presente momento não há uma produção contundente dos legislativos e executivos de Estados e Municípios (a fim de adequar às normas para aplicação em seus âmbitos). Ressalte-se que legislar sobre o tema é da competência de todos os Entes, inclusive os Municípios de forma suplementar (Art. 30, II, CF).

\subsubsection{Normas sobre A/ternative Dispute Resolution nos Estados da Federação}


$\mathrm{Na}$ esfera estadual, o Estado de São Paulo elaborou decreto que regulamenta o tema da arbitragem, trata-se do decreto 64.356/2019, o Rio de Janeiro também regulamentou a matéria por meio de decreto, qual seja o decreto 46.245/2018, de modo pioneiro o Estado de Minas Gerais já havia legislado sobre a matéria antes de mesmo da nova lei de arbitragem, a lei mineira é do ano 2011 (Lei 19.477). Também por meio de norma legal recentemente o Estado do Espírito Santo aplicou o tema à sua Administração Pública por meio da lei 10.885/2018. Em Goiás a lei existente é mais generalizada abrangendo também a mediação, trazendo além dos dispositivos referentes à Arbitragem, dispositivos que aplicam normas similares à da nova lei de mediação ao Estado, as disposições estão contidas na Lei Complementar 144/2018. Semelhante ao que ocorre em Goiás, também no Pará, que criou a Lei Complementar 121, promulgada em 2019, que é mais ampla dispondo também sobre a mediação e a conciliação. No Estado de Rondônia, a lei 4.007/2017, aplica à arbitragem àquele Ente Federativo. $O$ Estado de Pernambuco regulamentou a matéria na lei 15.627/15. Situação semelhante ocorre no Estado da Paraíba que em setembro de 2019 discutia em sua Assembleia Legislativa a aprovação de uma lei regulamentando a Arbitragem envolvendo àquela Unidade da Federação.

No que se refere à mediação e também da conciliação encontramos normas direcionadas apenas para estas espécies de ADR é o caso da lei 14.794/15, do Estado do Rio Grande do Sul. Destaque-se ainda a existência da Resolução AGE-MG 08/19 que regulamenta o funcionamento de Câmara de Prevenção e Resolução Administrativa de Conflitos - CPRAC, do Poder Executivo no Estado de Minas Gerais. Há Câmara Administrativa de Solução de Conflitos (CASC) semelhante no Estado do Rio de Janeiro desde o ano de 2016, todavia especializada em saúde. (CASC, 2016). Assim como há Câmara para prevenção de conflitos especializada em educação no âmbito do Distrito Federal. (SECRETARIA DE ESTADO DE EDUCAÇÃO DO DISTRITO FEDERAL, 2018). Há na Bahia uma Câmara voltada para Arbitragem, Mediação e Conciliação envolvendo a Administração Pública, instalada em 2018. (ASSOCIAÇÃO DOS PROCURADORES DO ESTADO DA BAHIA, 2018).

Cite-se que observando os sítios eletrônicos oficiais dos Estados e suas procuradorias é possível constatar ações institucionais importantes sobre o tema. No Estado de Santa Catarina durante este ano foi publicado no sítio eletrônico oficial de 
sua Procuradoria o interesse daquela Unidade da Federação no tema, ocorrendo reunião com organização especializada em Arbitragem. O Estado da Paraíba que em setembro deste ano discutia em sua Assembleia Legislativa a aprovação de uma lei regulamentando a Arbitragem envolvendo àquela Unidade da Federação. No ano de 2018 foi promovido pela Controladoria Geral do Distrito Federal curso para formação de mediadores voltados especificamente para a Administração Pública. $O$ assunto também foi recentemente discutido (em 08 de novembro de 2019) no Estado do Alagoas.

Observa-se assim que, considerando pesquisa junto aos sítios eletrônicos oficiais dos poderes executivo e legislativo dos Estados e do Distrito Federal, é possível afirmar que apenas nove dos vinte e seis Estados (mais o Distrito Federal) regulamentaram o tema, ou seja as ADR até o momento estão aptas para serem aplicadas com maior segurança jurídica apenas a 30\% das Unidades da Federação, pois apenas em tal fração há normas visando a aplicação das ADR em seu âmbito, mesmo havendo leis nacionais que pacificaram a possibilidade de utilização dos mecanismos no âmbito nacional desde 2015.

\subsubsection{Normas sobre ADR nos Municípios}

Tornar-se-ia hercúlea e inapropriada uma pesquisa e exposição sobre normas de 5.569 municípios, portanto tomou-se por base o relatório do Conselho Nacional de Justiça de 2011, quando tal instituição enumerou os maiores litigantes do país, em especial os 100 maiores, tomando dados das Justiças Estadual, Federal e do Trabalho e realizando também uma média das três, elencando assim os 100 litigantes "campeões", dentre os quais sem nenhuma surpresa figuram 37 municípios - Como dito ao início deste trabalho a Fazenda, incluindo os municípios, são repeat players - os quais tomamos por amostragem a fim de verificar a existência (dentre as normas municipais) de leis, decretos ou resoluções que apliquem alguma ADR aos seus âmbitos. 
Citem-se os municípios pesquisados, extraídos da pesquisa do Conselho Nacional de Justiça: Municípios de Santa Catarina; Município de Goiânia; Município de São Paulo; Município de Mauá; Município de Jaboatão dos Guararapes; Fazenda Pública de Belo Horizonte; Município de São José do Rio Preto; Município da Estância Balneária de Itanhaém; Município de Sorocaba; Município de Itaquaquecetuba; Município de São Vicente; Município de Maceió; Município de Indaiatuba; Município de Cotia; Município de São Luís; Município de Embu Guacu; Município de Jacareí; Município de Osasco; Município de Mococa; Município de Porto Alegre; Município de Caldas Novas - GO; Município de Limeira; Município de Osório; Fazenda Pública do Município de Juiz de Fora; Município de São José dos Campos; Município de Campinas; Município de Carapicuíba; Município de Suzano; Município de Mogi das Cruzes; Município da Estância Turística de Ribeirão Pires ; Município de Aparecida de Goiânia; Município de Lençóis Paulista ; Município de Franca; Município de Santa Isabel; Município de Poá; Município da Estância Balneária de Praia Grande; Município de Aracajú - SE. Ressalte-se que foram mantidas as nomenclaturas das municipalidades conforme constavam na pesquisa do Conselho Nacional de Justiça. (CONSELHO NACIONAL DE JUSTIÇA, 2012).

Dentre os municípios citados, o Município de Florianópolis (Capital do Estado de Santa Catarina), promulgou a recente Lei Complementar 664 de 2019, que acrescenta dentre as atribuições da Procuradoria Geral daquele Município a Conciliação e a Mediação, coordenada com atribuição de agente público específico dentro do órgão.

O Município de Goiânia possui uma lei que prevê a possibilidade de Arbitragem mas apenas para relações entre o Município e Empresas de Pequeno Porte e Microempresas, já há algum tempo, qual seja a Lei 8937/10, situação semelhante ao Município de Jacareí que possui a Lei 5.591/11, no de Ribeirão Pires por meio da Lei 5.418/10 e no de Poá (Lei 3.436/2010), no mesmo sentido de Goiânia.

Já citamos que o Município de São Paulo foi pioneiro ao regulamentar o dispute board em território nacional, possui uma disposição em sua lei de PPPs que autoriza a Arbitragem e a Mediação e também uma lei que cria Câmaras de Conciliação na área da educação. (Lei 16.134/15), todavia ainda não possui uma lei 
geral para ADR em seu âmbito. Belo Horizonte a semelhança de São Paulo possui permissão da realização de arbitragem em sua lei de PPPs (Lei 9.038/05), mas ainda não possui uma regulamentação geral do tema, caso idêntico ao dos Municípios de São Vicente (Lei 21.009/09), Cotia (1.742/2012), São Luís (4.894/07) e Carapicuíba (3.126/2011). Assim também ocorre com o Município de Sorocaba com sua lei de PPPs (Lei 10.474/13).

Sorocaba possui uma lei que regulamenta a mediação e a conciliação para a Administração Pública em geral em seu âmbito (Lei 11.777/2018), enquanto Mogi das Cruzes prevê a Arbitragem não só para PPPs (Lei 6.815/13) mas também para as concessões municipais (Lei 4.834/98). Praia Grande possui a previsão das PPPs (LC 740/2017), mas também há Decreto para Mediação e Conciliação no âmbito de sua Ouvidoria (Decreto 6.659/2019). Por sua vez o Município de Itaquaquecetuba possui a previsão de realização de ADR no âmbito da regularização fundiária, prevendo essas modalidades na Lei de Regularização Fundiária daquele Município (Lei 3.474/2018).

A seu turno o Município de Osasco assinou termo de parceria em 24/03/2018 com o TJ-SP a fim de estimular as ADR e evitar a judicialização (CASTRO, 2018), embora na legislação local só possua norma similar à de outros Municípios prevento apenas Arbitragem para PPPs. O Município de Porto Alegre possui Câmaras de Mediação e Conciliação (Lei 12.003/16), bem como a possibilidade de Arbitragem em PPPs (Lei 9.875/05). No Município de Juiz de Fora existe o Decreto 13.600/2019 que insere nas atribuições de sua Controladoria Geral a promoção de Conciliação ou Mediação com os usuários de serviços públicos, situação semelhante a do Município de Suzano. Por fim a Lei Orgânica do Município de Aracaju prevê a possibilidade de utilização da Arbitragem no bojo dos processos de desapropriação.

Ressalte-se também no âmbito dos Municípios algumas importantes ações institucionais sobre o tema:

Aparecida de Goiânia instalou em 11 de Junho do ano passado (2018) uma Câmara de Mediação e Conciliação a fim de diminuir os processos no Judiciário local. Jaboatão dos Guararapes instalou uma Câmara de Conciliação, Mediação e Arbitragem com intensa atividade de sua Procuradoria Geral, no ano de 2017. Franca Instalou em parceria com o Judiciário e a Polícia Militar sua terceira Câmara de 
Soluções de Conflito em setembro de 2019 e o Município de Santa Isabel possui parceria com o TJ SP possuindo no Município um núcleo do CEJUSC a disposição dos Munícipes.

Observe-se que dentre os Municípios, de acordo com pesquisa realizada junto aos sítios eletrônicos oficiais de seus Poderes Executivo e Legislativo, bem como de suas Procuradorias, que mais litigam no Brasil poucos possuem norma própria para ADR adequadas a sua realidade, alguns dos que possuem normas o fato ocorre apenas pelo fato de espelharem a norma federal (caso das PPPs), se assim não $\mathrm{o}$ fosse talvez sequer haveria alguma norma sobre $\mathrm{o}$ tema em tais municipalidades. Doze dentre os trinta em sete Municípios repeat players não possuem normas sobre o tema, quase um terço. Logo, é possível afirmar que no âmbito dos Municípios também é necessária produção normativa sobre o tema.

\section{A OTIMIZAÇÃOdA APLICAÇÃO DOS MEIOS ALTERNATIVOS DE SOLUÇÃO DE CONFLITOSNA MAIOR PARTE DA ADMINISTRAÇÃO PÚBLICA BRASILEIRA}

Baseado no que foi exposto é possível afirmar que embora o legislador federal e nacional intencionasse as ADR com o intuito de promover o término dos conflitos de forma célere e econômica, em especial no âmbito do Direito Administrativo, tal finalidade esbarra na falta de efetividade e aplicabilidade por Estados e Municípios, os quais estão inseridos na Administração Pública sem os quais as celeridade e economia almejadas não alcançaram uma potencialização de eficiência.

Para tanto, sugerem-se algumas soluções que eventualmente poderiam ser implementadas em toda a Federação. Quais sejam: Alçar as ADR a um patamar de Política Pública, traçar um diálogo institucional permanente sobre o tema, Promover um incentivo para a adequação do jurista às ADR e Promover um incentivo educacional para as gerações futuras; sobre as quais passa-se a expor. 


\subsection{ADR como Política Pública Nacional}

Não obstante legislar ou normatizar um tema não seja suficiente para a sua efetivação, suplementar e regulamentar as normas já existentes é uma importante fase para tal, pois estabelece adequações a realidades distintas e fornece respaldo jurídico ao agente público que irá executar os atos. Devemos lembrar que nas normas existentes na atualidade as Procuradorias Gerais de Estados e Municípios são as principais instituições que atuam nas ADR que envolvem a Administração, assim como a AGU na União, logo os Procuradores de Estados e de Municípios que ainda não normatizaram o assunto certamente não gozarão de segurança para atuarem de forma colaborativa na ausência de norma que os embase. 0 princípio da legalidade (Art. 37, caput, CF) deve ser respeitado, não obstante ser passível de releituras mais contemporâneas (neste caso especificamente a juridicidade não é suficiente), posto que os Procuradores precisam de um norte e de padronização para poderem agir de modo preciso e adequado. Como preferem alguns doutrinadores as soluções alternativas não deveriam ser chamadas de alternativas, mas adequadas. Por exemplo há Municípios com orçamentos menores que não possuem a urgência de normatização sobre Arbitragem, uma vez que esta ADR é mais adequada a contratos de maior vulto econômico, mas podem necessitar da Mediação que se adequa a conflitos em geral inclusive os de menor vulto econômico; logo para fins de adequação faz-se necessário normatização do tema em Estados e nos Municípios que em sua maioria não a possuem.

Portanto fala-se em uma Política Pública visando à economia dos Entes Públicos e a satisfação do administrado, em uma verdadeira Administração Pública de Resultados, incluindo este tema na agenda de Estados e Municípios. Agentes Públicos, sejam mandatários eleitos, sejam procuradores ou servidores em geral podem atuar de modo colaborativo à edição de normas no âmbito de seus Entes. Defende-se que, a fim de evitar morosos trâmites políticos junto ao legislativo, seja priorizada a elaboração de decretos, escolha mais interessante em relação à elaboração de lei (opção adotada pelos Estados do Rio de Janeiro e de São Paulo) sem riscos de inconstitucionalidade, uma vez que tratam-se de decretos no exercício do Poder Regulamentar da Administração Pública e que não exorbitam tal poder, 
pois o Legislador Nacional já autorizou a matéria (Nova Lei de Arbitragem e Nova Lei de Mediação) o Chefe do Executivo do Ente Respectivo se limitará a detalhar a lei no âmbito de seu respectivo Ente Político.

\subsection{Necessidade de um diálogo institucional permanente sobre o tema}

A Administração Pública é exercida em todos os Entes e em todos os Poderes da República, o dever constitucional de eficiência é igualmente de todos, em especial dos órgãos jurídicos por força das atuais Normas Fundamentais do Processo. Logo, Procuradorias, Ministério Público, Defensoria e Judiciário devem unir-se com esta finalidade.

Os executivos dos Municípios devem buscar celebrar convênios em geral com o Poder Judiciário (a exemplo do Município de Osasco citado em tópico anterior), ambos os Entes Federados (Estado e Município) obterão resultados satisfatórios com este diálogo. Cite-se, por exemplo, a possibilidade do Judiciário, como Poder dotado de autonomia financeira e considerável infraestrutura, fornece espaço a Municípios de menor número de habitantes para instalação de Câmaras especializadas e realização das Mediações e Conciliações nos Fóruns de tais comarcas, por meio de convênios justos para o Judiciário e para o Município, tais iniciativas trariam além de eficiência administrativa e economia processual a satisfação do interesse dos próprios cidadãos destas Municipalidades que teriam seu acesso à Justiça e o diálogo com a Administração Pública facilitados, ressalte-se este tipo de convênio com o Judiciário já ocorre com alguns Estados e Municípios (Exemplos de Rio Grande do Sul e do Município de Santa Isabel) e urge ser replicado nos demais Estados e Municípios em especial naqueles que oneram a si próprios e ao Poder Judiciário com excessos de Processos Judiciais.

Parcerias entre Estados que já normatizaram o tema e Municípios que ainda não normatizaram também seriam interessantes, posto que a expertise dos Estados poderia ser compartilhada com os Municípios o que fomentaria a consequente normatização pelas Municipalidades e aplicação técnica.

\subsection{Incentivar a adoção do jurista e operador do direito às ADR}


A mudança cultural só é possível com um processo gradual de práticas e criação de hábitos. O profissional do Direito que conhece as ADR e conhece a possibilidade de aplicá-las à Administração deve incentivar a sua utilização. O servidor público tem o dever de eficiência, logo sua atuação deve ter por finalidade a otimização do serviço. Em certa medida estas sugestões de efetividade das ADR estão conectadas, pois os Procuradores de Estados e Municípios podem propor a seus pares, aos Procuradores Gerais e aos Chefes dos Executivos a criação de normas para a adequação de seu trabalho e com a sua criação as Procuradorias devem buscar a padronização de sua atuação nestes meios a fim de gerar segurança jurídica não somente aos profissionais, mas também aos administrados.

O Ministério Público e a Defensoria Pública também podem ser um importante input neste processo buscando privilegiar os Termos de Ajustamento de Condutas (TACs) e soluções consensuais com Estados e Municípios no lugar da judicialização, o diálogo permanente entre MP, Defensoria e Advocacia Pública é essencial para o desenvolvimento de uma cultura menos litigiosa.

A atuação dos advogados privados é igualmente fundamental neste processo, pois os advogados privados recebem as demandas dos cidadãos e podem ser o primeiro canal para uma solução consensual ou arbitral, o advogado pode propor a seu cliente a negociação, a conciliação ou a arbitragem com o Poder Público. Pode dialogar com a Administração Pública e com seus administrados e ser a ponte da consensualidade. Hodiernamente fala-se no rompimento da Summa Divisio e em uma área cinzenta onde o interesse público e o privado já não são mais tão evidentes, sem nenhuma acepção patrimonialista, mas sim em uma ideia constitucional de que os direitos individuais fundamentais são tão importantes quanto às garantias de toda a coletividade. (OLIVEIRA, 2018, p. 15-17).

Sendo assim todas as Funções Essenciais à Justiça teriam seu papel, principalmente fomentando a cultura da pacificação do conflito incentivando, promovendo atividades educacionais para profissionais que já estão atuando, mas que visam se adaptar ao momento que o Direito brasileiro vive.

\subsection{Promover um incentivo educacional para as gerações futuras}


É necessário refletir sobre a "cultura da sentença", urge que a nossa sociedade passe a observar que o processo não é somente uma capa de papelão e um amontado de papeis, ou um conjunto de dados em um sistema eletrônico. 0 processo são tributos, dinheiro de todos os brasileiros que estará satisfazendo o seu objetivo somente se for bem empregado. Campanhas de conscientização em uma maior amplitude em relação àquelas que já são realizadas pelo $\mathrm{CNJ}$, uma adequação dos cursos jurídicos ao Sistema de Múltiplas Portas, a inclusão de disciplinas obrigatórias sobre mediação e soluções de conflitos nos diferentes níveis de ensino a fim de estimular uma mudança de paradigma cultural podem ser bem vindas a exemplo do que vem ocorrendo com disciplinas como a educação financeira nos ensinos de base, a inclusão desse tipo de disciplina no nível superior em geral e em especial nos próprios cursos de Direito seria de importante avanço para a formação de um profissional do Direito que pensa antes de judicializar, que negocia, que busca soluções consensuais, assim como alavancaria o ingresso de profissionais às carreiras jurídicas de Estado que oxigenando a visão da solução dos conflitos, estes são alvos a serem perseguidos na atualidade.

\section{CONCLUSÃO}

A Constituição Federal e o Legislador Brasileiro buscam uma Administração Pública e um modelo processual célere, eficiente e satisfativo, fala-se atualmente em direito fundamental à boa administração. $O$ cenário que se desenvolvia era de um processo judicial, em especial envolvendo a Administração Pública; lento, caro e ineficiente. A criação de leis no âmbito nacional não foi suficiente para distribuir por todo território nacional o manejo das ADR, posto que a maior parte dos Estados e Municípios ainda não possui legislação sobre o tema inviabilizando sua segura aplicação. Para o operador do Direito há um protagonismo do processo judicial como o meio de resolução de conflito por excelência, a judiciliazação ocupa a maior parte do conteúdo acessível na formação do jurista, embora o Código de Processo Civil de 2015 tenha previsto um novo modelo de acesso à Justiça, ampliando este princípio constitucional a uma visão não restritiva ao Judiciário, mas sim à solução do litígio e 
também incentivando a uma advocacia cooperativa. A realidade ainda demonstra que os profissionais do Direito possuem um perfil mais voltado ao processo judicial de modo litigioso. Essa realidade se aplica tanto àqueles que estão ingressando na profissão, quanto aos que nela estão há alguns anos, tanto em relação ao setor público quanto ao privado, sendo a natureza do problema educacional e cultural. Estes fatos urgem a necessidade de atitudes políticas, institucionais, culturais e educacionais por parte de agentes políticos, servidores, operadores do Direito em geral e dos educadores dos cursos jurídicos a fim de alcançar uma Administração Pública de Resultados em relação aos conflitos que surgem no Direito Administrativo Brasileiro.

\section{REFERÊNCIAS}

ASSOCIAÇÃO DOS PROCURADORES DO ESTADO DA BAHIA. Bahia ganha a sua primeira câmara de mediação, conciliação e arbitragem de uma associação de carreiras jurídicas. Salvador: APEB, 2018. Disponível em: http://www.apeb.org.br/noticias1.asp?reg=485. Acesso em: 15 nov. 2019.

CASC. Câmara Administrativa de Solução de Conflitos (CASC). [S. I.], 2016. Disponível em: https://pge.rj.gov.br/mais-consenso/camara-administrativa-desolucao-de-conflitos-casc. Acesso em: 25 nov. 2019.

CASTRO, Paulo Rabello de. 0 mito do governo grátis: o mal das políticas econômicas ilusórias e as lições de 13 países para o Brasil mudar. Rio de Janeiro: Edições de Janeiro, 2014.

CASTRO, Talita. Prefeito de Osasco assina termo de compromisso com TJ-SP. Cidade de Osasco, Osasco, mar. 2018. Disponível em: http://www.osasco.sp.gov.br/noticias/prefeito-de-osasco-assina-termo-decompromisso-com-o-tj-sp. Acesso em: 15 nov. 2019.

CONSELHO NACIONAL DE JUSTIÇA. 100 maiores litigantes 2012. Brasília, DF: CNJ, 2012. Disponível em: https://www.cnj.jus.br/wpcontent/uploads/2011/02/100_maiores_litigantes.pdf. Acesso em: 15 nov. 2019.

IPEA. Comunicado IPEA 83. [S. I.], 2011. Disponível em: http://www.ipea.gov.br/portal/images/stories/PDFs/comunicado/110331_comunicado ipea83.pdf. Acesso em: 25 out. 2019. 
JORNAL NOVO HAMBURGO. Quanto custa para os municípios os processos judiciais de saúde. [S. I.], 2019. Disponível em:

https://www.jornalnh.com.br/noticias/regiao/2019/06/2434655-quanto-custa-paraos-municipios-os-processos-judiciais-de-saude.html. Acesso em: 15 nov. 2019.

LOCKS, Juliane. O uso da arbitragem pela administração pública à luz dos princípios constitucionais do art. 37, caput. In: LOCKS, Juliane. Arbitragem e administração pública. 2012. 33 p. Trabalho de Conclusão de Curso (Bacharel em Direito) Pontifícia Universidade Católica RS, Rio Grande do Sul, 2012. Disponível em: http://www3.pucrs.br/pucrs/files/uni/poa/direito/graduacao/tcc/tcc2/trabalhos2012_ 1/juliane_locks.pdf. Acesso em: 03 nov. 2019.

OLIVEIRA, Rafael Carvalho Rezende. Curso de direito administrativo. 6. ed. rev., atual. e ampl. São Paulo: Forense, 2018.

PINHO, Humberto Dalla Bernadina. Direito processual civil contemporâneo. 8. ed. São Paulo: Saraiva, 2018.

PINHO, Humberto Dalla Bernadina; NUNES, Patrícia Elael. A confidencialidade e suas peculiaridades no procedimento de mediação envolvendo a fazenda pública. [S. I.]: Academia, 2017. Disponível em:

https://www.academia.edu/36470896/A_CONFIDENCIALIDADE_E_SUAS_PECULIARI DADES_NO_PROCEDIMENTO_DE_MEDIAC_A_O_ENVOLVENDO_A_FAZENDA_PU_BLI CA_13122017.docx. Acesso em: 28 out. 2019.

PORTO, Antonio José Mastrello. Análise econômica do direito (AED). Rio de Janeiro: FGV, 2013. Disponível em:

https://direitorio.fgv.br/sites/direitorio.fgv.br/files/u100/analise_economica_do_direit o_20132.pdf. Acesso em: 27 out. 2019.

RODRIGUES, Marco Antonio. A fazenda pública no processo civil. 2. ed. São Paulo: Atlas, 2016.

SECRETARIA DE ESTADO DE EDUCAÇÃO DO DISTRITO FEDERAL. Portaria no $\mathbf{3 5 2}$, de 30 de outubro de 2018. Disciplina as atividades de mediação para solução de conflitos entre servidores no âmbito da Secretaria de Educação do Distrito Federal, bem como a rotina procedimental a ser executada pela Gerência de Mediação de Conflitos. Brasília, DF: SEEDF, 2018. Disponível em: http://www.sinj.df.gov.br/sinj/Norma/7ce6d07e51ee4c3db74508fdca5e2f1b/Portaria _352_30_10_2018.html. Acesso em: 15 nov. 2019. 
WATANABE, Kazuo. A cultura da sentença e a cultura da pacificação. In: MORAES, Maurício Zanoide; YARSHELL, Flávio Luiz (coord.). Estudos em homenagem à professora Ada Pellegrini Grinover. São Paulo: DPJ Ed., 2005. Disponível em: https://edisciplinas.usp.br/pluginfile.php/3079662/mod_resource/content/1/1.1.\%20 Kazuo\%20-\%20Cultura\%20da\%20sentenca\%20e\%20da\%20pacificao.pdf. Acesso em: 27 out. 2019.

Recebido em 13/02/2020.

Aceito em 19/03/2020. 